\title{
Resisting coherence: trans men's experiences and the use of grounded theory methods
}

\section{Chase J. Catalano}

To cite this article: D. Chase J. Catalano (2017) Resisting coherence: trans men's experiences and the use of grounded theory methods, International Journal of Qualitative Studies in Education, 30:3, 234-244

To link to this article: http://dx.doi.org/10.1080/09518398.2016.1254301

曲 Published online: 16 Jan 2017.

Submit your article to this journal $₫$

Q View related articles $\sqsubset$

View Crossmark data \lceil 


\title{
Resisting coherence: trans men's experiences and the use of grounded theory methods
}

\author{
D. Chase J. Catalano
}

College Student Personnel Program, Western Illinois University, Macomb, IL, USA

\begin{abstract}
In this methodological reflective manuscript, I explore my decision to use a grounded theoretical approach to my dissertation study on trans* men in higher education. Specifically, I question whether grounded theory as a methodology is capable of capturing the complexity and capaciousness of trans*-masculine experiences. Through the lenses of social justice and Critical Trans Politics I question whether theory generation with so little published about trans* men in research puts limitations on the possibilities of liberation for trans* men. I suggest researchers consider utilizing exploratory research to understand the experiences of trans* men instead of theorizing about their lived experiences.
\end{abstract}

\section{ARTICLE HISTORY}

Received 14 May 2016 Accepted 21 October 2016

\section{KEYWORDS}

Transgender; higher education; grounded theory; social justice; Critical Trans Politics

\section{Introduction}

One of my favorite podcasts is This American Life, a weekly show from National Public Radio that shares stories, often as first-person narratives, bringing complex nuances to explore a different topic each week (www.thisamericanlife.org/about-our-radio-show). As an educator who practices dialogic and engaged pedagogies, which encourage development of personal narrative and perspective taking (Gurin, Nagda, \& Zúñiga, 2013; hooks, 1994; Maxwell, Nagda, \& Thompson, 2011) it makes sense that I would be drawn to a radio show based on storytelling. As a qualitative researcher, I center participant voices to embrace the value of storytelling.

Episodes do not offer any (overt) theorizing about the principles that form the stories; instead they are loosely organized around a theme, almost as if the producers stopped after a surface level of data analysis. This American Life reminds me of why I eventually struggled with using grounded theory as the methodology for my dissertation research. I was resistant to offering any suppositions to explain, rather than just describe, the experiences of trans* men in collegiate settings. I wanted to let the participants and their stories speak for themselves. As I engaged in data analysis, I began questioning whether grounded theory methodology was capable of capturing the complexity and capaciousness of trans*-masculine experiences. In hindsight, my issues are not with grounded theory per se, but instead with how the 'dominant traditions of qualitative inquiry fail to address the fundamental philosophical underpinnings of in/equity in higher education' (Pasque, Carducci, Kuntz, \& Gildersleeve, 2012, pp. 3-4). In this article, I illuminate how my dissertation research used basic grounded theory guidelines and shared an allegiance to grounded theory principles, but resisted the positivistic assumptions and roots that might have forced data into an ill-fitting theoretical conceptualization (Charmaz, 2006). 
A review of previously published literature on trans* students raised some concerns for me about the minimal use of empirical data to support policy and practice recommendations (Catalano, 2015b). In my research on undergraduate trans* men in higher education (Catalano, 2014), I sought to address the absence of empirical and theoretical research on this student population through using grounded theory methods. In this article, I explore how I chose grounded theory methods and why, in the end, I discarded developing a substantive theory of trans* men's experiences in higher education because I felt the move to theorize was 'too soon.' I explain why I used qualitative descriptive method in my dissertation to present my data to avoid oversimplifying identity, community, and experience. Finally, I outline how I determined it was premature to generate a theory about trans* men and other understudied populations. I determined that for my research, theorizing about trans* men collegians may work in contradiction to developing practical changes to achieve any form of trans* liberation.

\section{A tentative note on terminology}

Throughout this article I will use trans* to refer to a broad constellation of gender identities that falls outside of the strict gender binary of male-assigned men and female-assigned women, as a way to 'open up transgender or trans to a greater range of meaning' (Tompkins, 2014, p. 26). Research on trans* identities is still relatively recent in the study of higher education, so many publications begin with sentences or even paragraphs providing definitions of terms of identity. When language clarification precedes research and analysis, even for the edification of the reader, it has the (unintentional) effect of hiding the complications and nuances of those same identities the research may have sought to explore (e.g. Henderson, 2014; Porter \& Dean, 2015). An initial attention on language at the onset of an article simultaneously produces education and objectification. In the context of higher education research, teaching about trans* identities is important because it encourages recognition and visibility of a population of students who may be invisible on many campuses (Pope, Mueller, \& Reynolds, 2009). However, troubling is that visibility and recognition through language imply a coherence and consistency of experience that does not exist among trans* people (Valentine, 2007). For lack of a better phrase, trans* terminology implies a conformity of identity and experience that can lead to oversimplification and potential dehumanizing quantification of trans* lives. As Pasque et al. (2012) noted:

Conceptualizing stable identities allows for a politic of identity to form, which dangerously sets expectations of conformity, inherently relies upon us-versus-them logics of conflict, and becomes easily quantified into notions of human capital, where some capital will become more valuable than others in crass calculations of human experience. (p. 12)

I do not want to diminish the discursive power of language (Butler, 1990), and I want to direct attention to how an emphasis on language diffuses the content of research. A false definitional consistency simplifies trans* experiences to a degree that constitutes symbolic violence (Spade, 2011). As Spade (2011) stated, 'For trans people, administrative gender classification and the problems it creates for those who are difficult to classify or are misclassified is a major vector of violence and diminished life chances and life spans' (p. 142). In higher education, the obsessive focus on clarifying language of trans* identities serves to distract attention that should be given to practical concerns that effect trans* people's life chances, such as limitations with gendered housing options, inadequate health care, documentation that requires legal names, and how employment discrimination means trans* people are overeducated, but underemployed (Spade, 2006). Efforts to unify language also obfuscates how language fails to capture the complexity of trans*ness, and it objectifies trans* students as an abstraction that can be solved by finding the best language to summarize a group's presumed essential nature. In essence, to articulate a commonality of language is the first step in theory-making, as it implies a consistency that can then be used to posit a framework to explain an experience. Theory-making is both powerful and not neutral (Charmaz, 2006); it frames what can be known about trans*ness and therefore forecloses other possible knowledge. 


\section{Uses of grounded theory}

In selecting methodology for my dissertation research, some were immediately eliminated as unsuitable. With regard to quantitative methods, the number of trans* students in college remain elusive and unknown, by choice and by administrative design, and the lack of 'hard' data allows institutional structures to proceed as if trans* students are not significant enough to give attention (Beemyn, 2003; Spade, 2011). As Currah and Stryker (2015) wrote, 'To regularize a population is to flatten its zoetic confusions of movement and form, of time and space, of doing and being, into neat two-dimensional axes specifying static properties and numbers' (p. 2). I chose not to use numbers to communicate trans* men's experience in higher education because administrative processes provide no way to find or count them at most institutions. I chose qualitative methods to potentially provide nuanced stories by those trans* men in college who were willing to be found. I chose qualitative methods because the 'imperative to be counted becomes another kind of normativizing violence that trans subjects can encounter and hence another problematic to be critically interrogated by the field of transgender studies' (Currah \& Stryker, 2015, p. 4). I was interested in the stories of trans* men in college, and I wanted to understand the vast and complex experience that qualitative methods would allow me to explore. Qualitative methods were also aligned with my social justice education framework that would allow me to 'enter the world of the participants as learners (not experts) and as a result, share the power of knowledge and decrease the likelihood of marginalizing the research participants' (Pope et al., 2009, p. 644). The significance of my study would be rooted in the voice of my trans* men participants and how they made meaning of their experiences in college as trans* men.

Grounded theory, as a specific methodology of qualitative research, would allow me to 'get out into the field to discover what is really going on' (Brown, Stevens, Troiano, \& Schneider, 2002, p. 174) with trans* men at colleges and universities. When I began the process of writing my dissertation proposal, I started with my research questions. I knew that I wanted to study the experiences of transgender ${ }^{1}$ men at colleges and universities in the United States. I was able to make quick distinctions about the specifics by narrowing down an accessible participant pool: identified under the umbrella term of transgender or trans man; enrolled for at least two consecutive semesters as an undergraduate student in a non-virtual college or university in the New England region of the United States; speak English; and born and raised in the United States (Catalano, 2014). My knowledge of grounded theory was based on what I learned from research classes in my doctoral program and reading about it on my own. My initial hope was to generate a substantive theory of trans* masculinity to explain how my participants made meaning of negotiating masculinity as people who were assigned female at birth. An initial impetus behind my work was to offer a theoretical something that would be based on empirical research because there was sparse theorizing research on trans* collegians.

I deemed the use of grounded theory as an appropriate method to describe the experiences of trans* men in a collegiate setting because '[t]he procedures of grounded theory are designed to develop a well integrated set of concepts that provide a thorough theoretical explanation of social phenomena under study. A grounded theory should explain as well as describe' (Corbin \& Strauss, 1990, p. 5). Through my call for participants, I hoped my insider status (Preissle, 2006) as a trans* man would help build rapport in the effort of extending a form of kinship to participants; to keep them from feeling like 'objects of curiosity' (Pusch, 2005). At the same time, as much as I hoped my participants would articulate experiences that would align with my own, I did not go into any interviews expecting similarities just because we shared an identity. As Preissle (2006) stated, 'Insiders bring their local knowledge to interrogate scholarly knowledge in ways that enrich both' (p. 690). I disclosed my identity as a trans* man in my call for participants and during interviews answered their questions about my experiences as someone who experienced some hurdles while attending and working in institutions of higher education. I wanted to avoid any overt pressure my participants might feel to justify their experiences to an outsider. I never claimed my approach was rooted in objectivism, nor was I seeking to create a positivist theory (Pasque et al., 2012). I approached interviews with my participants with openness to their accounts because I did not want to presume a similarity of experience. 
I was inspired by the theoretical possibilities of my research because I thought I could build off of the previously published non-empirical literature about policy and practice changes to increase trans* student inclusion (Beemyn, 2002, 2003, 2005; Beemyn, Curtis, Davis, \& Tubbs, 2005; Beemyn, Domingue, Pettitt, \& Smith, 2005; Beemyn \& Pettit, 2006; Sausa, 2002). Clegg (2012) cautioned about theory in research when she stated, 'We may mis-represent the messy and complex endeavour of theorising and the dialectic between theory and data, which is not reducible to either inductive or deductive logic' (p. 407). I admit that my newly developing research practice was not duly cautioned by Clegg's (2012) warning. I wrote this article offers a reflective process of how I negotiated my methodological unease and re-presents it as the messy endeavor that led me to consider how 'classical' grounded theory methods (e.g. Corbin \& Strauss, 1990) of theory generating might portray a positivistic view of trans* men's collegiate experiences (Charmaz, 2006). When I considered the available literature on trans* collegians, a contemporaneous purpose for my research emerged; I wanted to address the needs of trans* men that came directly from their experiences. I became distracted by the lack of empirical research on trans* collegians, and gave little attention to the potential negative implications of theory-making about trans* masculinity (Catalano, 2015a, 2015b). Most published work on trans* students were focused on fixing the problems of exclusion and hostility in higher education on the structural, institutional, and interpersonal levels in such areas as 'health care, residence halls, bathrooms, locker rooms, records and documents, public inclusion, and programming, training, and support' (Beemyn et al., 2005, p. 90). Suggestions provided in previous publications offered recommendations that were practical, tangible, and material to assist improving experiences of trans* students. These recommendations are significant and broadly applicable, yet they lacked the empirical research to indicate that such changes would be effective, and many presumed a monolithic trans* student experience without addressing distinctions between trans* identities.

Pascarella (2006) cautioned against universalizing the impact of college experience, stating, 'Limiting one's vision to general effects can frequently be misleading and mask dramatic differences in the impact of an intervention or experience for different kinds of students' (p. 512). The specific focus of my research, on those who identified as trans* men, had the potential to expose their struggles and supports for the first time as a distinctive group under the trans* umbrella identity category. I believed my research questions, and semi-structured interview protocol (Charmaz, 2006) would allow me the ability to'generate a theory that accounts for a pattern of behaviour which is relevant for those involved' (Backman \& Kyngäs, 1999, p. 151). In the process of writing my dissertation, and moreover in the months that have passed since my defense, I found myself drawn to the work of Pasque et al. (2012) who urged higher education scholars to shift their critical eyes beyond content and 'extend such criticality to the very methodological assumptions that make such content visible in particular ways' (pp. 1, 2).

I am drawn to Pasque et al. (2012) and critical qualitative inquiry because it gives me the support to name how my dissertation research was mired in the tension between a positivistic vs. constructivist approach to grounded theory (Charmaz, 2006). As a doctoral student, I was overwhelmed with data (25 participants for my first qualitative study). I was also nervous to closely examine and scrutinize different types of grounded theory for fear I would get lost down a 'rabbit hole.' Even though Charmaz (2006) wrote that she viewed 'grounded theory methods as a set of principles and practices' (p. 8), I struggled to find my own agency to lean on her assertion. In my post-dissertation defense life, I feel an almost confidence to critically examine my choices in methods.

When I began to write my data chapters, I realized my methods did not work to support how I wanted to share my data. I used in vivo coding to 'preserve participants' meanings of their views and actions in the coding itself' (Charmaz, 2006, p. 55). I struggled in my efforts to begin to conceptualize a theory. To be clear, my rejection was not of theory, but rather the difficulty of generating theory from my data because I worried about the reductive action that did not work with my data (Clegg, 2012). First, the data themselves did not lend themselves to any form of cohesion that could be theorized. Similarities existed among participants, but there was nothing cohesive about their trans*ness that allows for a unified substantive theory of their gender identity. Their descriptions varied from trans*ness as temporary to trans*ness as enduring, passing as of primary importance and passing as invisibility, and 
conflicting views about embodiment (Catalano, 2015b). I felt there were too many tensions between their self-conceptions to allow for any rendering of identity through an identity development conceptualization. Second, I began to question whether the building of a theoretical model of trans* men's identity development might only serve to encourage assimilation into masculine hegemony, enhance already existing notions of 'authenticity' about trans*ness or 'real' men, or influence alignment with whatever theory I developed. Finally, I tried to find connections to current research, but the nascence of research on trans* men and trans* men in higher education could not support theorization about trans* men's identities. The virtual absence of research on trans* men, as well as rapid evolution within trans* communities, movements, and discourses, leaves little work to build off and too many questions untested and unanswered. In the next section I discuss how, upon closer examination of my theoretical framework of social justice, I made the decision to utilize different methodologies to communicate my findings.

\section{Social justice framework}

As previously stated, my initial emphasis of my work was based on my desire to offer a theoretical something that would be based on empirical research. I thought a theory was a way to broadly speak about the experiences of trans* men in higher education. At the same time, I understood what was needed was exploratory research to understand the actual experiences of trans* men. I offered a critique (Catalano, 2015b) of what it means to generate policy and practice that is not based in empirical research because the literature seemed to paint all trans* students with a single brush stroke. Thus, my research attention on trans* men needed to first attend to their actual experiences, which would surface their interactions with the policies and practices in higher education.

A social justice education framework encouraged me to think 'broadly about the intersection of individual and group identity(ies) is complicated by the ways in which identities are co-constructed and assigned meaning within oppressive systems'(Bell, 2007, p. 8). To understand such co-constructed meanings requires interactions with students who were struggling to be seen, to be understood, to be respected, and to thrive at their institutions. At the time of my research, there was a scant of literature on trans* students in higher education, so while I had concerns and critiques of what was happening at institutions, I chose not make any grand leaps of theory because I did not have data to substantiate my conjectures. Instead I chose to give attention to how transgender oppression (Catalano, McCarthy, \& Shlasko, 2007) manifested in the lives of my participants as evident in their stories.

Social justice also provides the tools for systemic/cultural, institutional, and interpersonal analysis of power, privilege, and oppression that impacts the lives of trans* men (Bell, 2007). The idea of praxis, the connection of theory to practice (Freire, 1970/1994), is foundational to social justice education. Bell (2007) offered 'theory also provides a framework for questioning and challenging our practices, and remaining open to creating new approaches as we encounter inevitable problems of co-optation, resistance, insufficient knowledge, and changing social conditions' (p. 2). In other words, social justice theory encourages the ongoing questioning of knowledge in an effort to understand the power dynamics, visible and invisible, entangled in the work of knowledge production. As a scholar committed to social justice, I did not want to consider identity, embodiment, and institutional barriers for trans* men as discrete topics, rather I wanted to offer these topics as interlocking with each other. As Pasque et al. (2012) emphasized,

As critical scholars intent on pursuing social justice in higher education research we cannot afford to abide by traditional epistemological formations that privilege the separation of bodies from minds, material conditions from discursive rendering, nor claims for holistic subjects and complete knowledge formations. (p. 44)

My commitment to social justice, and to the lives of my participants, honors a holistic that could not be fulfilled by creating a theory of trans* men's identity. The lives, words, and ideas of my participants were primary to conveying the significance of my research. Creating a theory of trans* men's identities had the potential to force coherence where I did not find any. 
In the end, despite the pressure to follow my research methods as planned, my resistance to the development of theory would not be assuaged. I wanted to stay close to the words of my participants, so I acknowledged my adherence to grounded theory guidelines and utilized qualitative descriptive to share my findings. I determined that theory development was not my aim, and instead focused on exploration, on the stories of my participants, and on their own terms. As Corbin and Strauss (1990) noted, 'A theorist works with conceptualizations of data, not the actual data per se' (p. 7), and I was not willing to step away from my data in a way that would be aligned with grounded theory methods. I am left questioning whether I could have constructed a theory if I had given more attention to Charmaz's (2006) constructivist approach to grounded theory. Instead I turned to qualitative descriptive methods to provide me the space to name experiences that were overlapping as well as outliers. Sandelowski's (2000) summary of qualitative descriptive methods notes the method does not require'a conceptual or otherwise highly abstract rendering of data' (p. 335). I presented my findings using thematic descriptions of the experiences of my participants. In this way, 'qualitative descriptive studies produced findings closer to the data as given, or data-near' (Sandelowski, 2010, p. 78). Qualitative descriptive studies are not devoid of theory, and instead focus on the interpretive 'spin' of the researcher (Sandelowski, 2010).

My choice to use qualitative descriptive method in my data presentation allowed me to remain 'amenable to obtaining straight and largely unadorned (i.e., minimally theorized or otherwise transformed or spun) answers to questions of special relevance to practitioners and policy makers' (Sandelowski, 2000, p. 337). Put another way, in resisting a theory, I staked a claim that my research contributes to practice and centers the voices of trans* men in higher education. As a framework, social justice requires a commitment to offer research that is connected to and informs practice in student affairs and higher education. In other words,

Social justice requires a commitment to connect the individual to the institutional to the social. Social justice demands a systemic point of view and commitment to systemic change. Social change is that which emerges from the critical commitment of praxis - moving the imagined into reality albeit in dynamic, pluralistic, idiosyncratic, and contextually contingent manifestations. (Pasque et al., 2012, pp. 7, 8)

Equity in higher education is a fundamental part of social justice work, and I was invested in my research adding to the literature in a way that produced institutional and systemic change for the inclusion of trans* men.

I am not claiming that theory generating is incompatible with institutional and systematic change recommendations in research, but rather that the contextual specificity of my research, the dearth of empirical research that preceded my research, and the incoherence of my participants' experiences was not best served by the production of a theory, however minor or substantive. This is a moment best served by trans* men as a population given opportunity for voice, not be enamored with existential concerns served by theorizing. In fact, as I elucidate in the next section, theorizing may interfere with effective action that would diminish possible liberation efforts for trans* men (Catalano, 2015a). The absence of published literature prior to 2005 signals an opportunity to consider the exploratory possibilities of research on trans* collegians in the hopes of intersectional, not just population specific, transformation (Spade, 2011).

\section{Critical Trans Politics and research}

Spade (2011) introduced Critical Trans Politics (CTP) as arguably the most inspiring analysis that critiques current trends in policies and systems, and offers space for critical dialogue about the future of trans* politics based on an intersectional framework. CTP does not seek to define trans* identity, but to look at the structures that impede, influence, regulate, and marginalize trans* lives. CTP connects with social justice in how it is 'process-oriented rather than end-oriented, practicing ongoing critical reflection rather than assuming there is a moment of finishing or arriving' (Spade, 2011, p. 189). Higher education research is already framed by practice and policy as it is context-specific, and student affairs practice is studied and reproduced, and regulated by policies (Clegg, 2012). Theorizing moves research 
further away from critical reflection instead of closer to moments of arrivals (commonalities within the data) and/or departures (divergences within the data) through trans*ness (Nicolazzo, 2016, in press).

CTP encourages critical reflection of experiences that takes into account temporality of trans*ness (Garner, 2014; Halberstam, 2005; Sullivan, 2006) and the specificity of the campus location and institutional structures. For instance, in my research I found that there were tensions within participants"campus-based communities about passing and embodiment versus transgressing gender norms' (Catalano, 2015 b, p. 420). Many participants struggled with the notion of being 'trans enough' as a measurement of their'authenticity' of transness and expectations about passing or resistance to being passed by others as either cisgender (Catalano, 2015b). To give attention to the theoretical similarities of trans*ness is important, but I am not yet convinced due to lack of empirical research that we are ready to theoretically explore the nuances that might be specific to the complexities of campus and geographic based trans* communities that influence who is (dis)connected to those communities. Not to not attend to the tension within campus-based communities, and instead theorize about transitioning as a practice of transness among trans* men would be to ignore the structures and systems that require bio-medical transition for recognition (Catalano, 2015b). I chose to not focus my dissertation on a theoretical approach to the cultural influence of the gender binary and bio-medical transition choices of my participants. I did not want to reinforce or create a new theoretical framework that would be harmful to my participants. Instead I described how bio-medical transition narratives caused doubts about being 'trans enough;' doubts for trans* men who bio-medically transitioned came from an absorption into the binary and invisibility, and those who did not bio-medically transition through lack of recognition as trans*, masculine, or not female (Catalano, 2015b).

In their work examining the discursive inclusion of trans* identities in LGBTQ centers on college campuses, Marine and Nicolazzo (2014) noted research utilizing critical theories should 'include a commitment to asking foundational questions about how power and dominance operate in institutions to replicate the status quo, and identifying how specific discourses function to communicate and reify existing power relationships' (p. 267). Extending their notion, I assert that research on trans* men's identities must not only include an examination of power, but must also start from the personal experiences of trans* men. For example, my research revealed that there was a lack of coherence across participants with language. Specifically, as I have written elsewhere:

Not all participants wanted to identify with trans (as a noun or as an adjective), and not all of them identified as trans men. In all cases, the words they used about their transness and gender conveyed their desires about transitioning. (Catalano, 2015b)

I chose to note the distinction between participant identities and reveal the divergence of their experiences instead of trying to force a coherence of experience that was so distant from their experiences as to make them unrecognizable. Such an approach was consistent with CTP's value of polyvocality, or the foregrounding of multiple voices and perspectives, even from within populations often thought of as monolithic (e.g. trans* men). Furthermore, when approached with a liberatory consciousness (Love, 2010), CTP can create conditions for change to combat inequity. As I have written elsewhere (2015a),

\footnotetext{
A liberatory consciousness provides opportunities for individual events to raise awareness, to engage in analysis, to shape actions, and to examine accountability. Inclusivity practices, policies, pedagogies, and engagement look different at each institution based on location, demographics, student services, academic collaborations, institution type, and other factors; developing a liberatory consciousness requires people, as individuals and in their institutional roles, to ask themselves and their colleagues about goals that support trans* people, and then ask how they can do it better. (p. 430)
}

By approaching research with the same investment in liberatory consciousness as is done in practice and policy decisions, then social justice and equity are possible.

Social justice requires an examination of power through the theory of oppression (Bell, 2007). Spade (2011) intentionally uses 'subjection' instead of 'oppression' because "'oppression" brings to mind the notion that one set of people are dominating another set of people ... Operations of power are more complicated than that' (p. 25). Spade's critique is notable because language used to critique power can be misused and co-opted to diminish the strength of the spotlight they put on marginalization, 
exploitation, powerlessness, violence, and cultural imperialism (Young, 1990). Yet, I am uninterested in parsing out the distinction between the language of oppression and subjection, as I think attention on language misdirects attention away from the most important project: a shared analysis of power that joins social justice and CTP. The focus of research, policy, and practice should be on how the hegemony of gender normativity influences the experiences of trans* collegians. CTP as a framework encourages methods that give voice to participants in an effort to engage in critical inquiry. Instead of searching for a singular narrative, research should seek out 'multiple, competing, and conflicting renderings of reality so as to offer up tensions where more deliberate and informed choices can be made' (Pasque et al., 2012, p. 13). The importance of research should be finding the tensions across experiences to encourage intersectionality and complexity.

In the research I conducted on trans* men (Catalano, 2015b), the most important finding was the lack of coherence because unknown at this time is what constitutes commonalities or coherence for an understudied population. We have yet to understand the specific dynamics of the multiplicity of trans* identities in collegiate settings. Trans* men in higher education had such low expectations for inclusion that acts of tokenization and an absence of physical violence were named as indicators of a supportive institutional environment (Catalano, 2015a). I encourage researchers to step toward complexity and question whether theorizing contributes to a CTP social justice project. To what extent does theorizing about trans* lives attend to experientially rich data? I argue that exploratory research may be the best way to avoid the reproduction of virtual equality (Vaid, 1995) and provide guideposts to examine accountability for the lives of trans* students on campuses. For example, participants in my research attended institutions that included gender identity and expression in their non-discrimination policies, but many reported being disappointed with the level of trans* inclusion on campus (Catalano, 2015a). Practical changes, research that offers suggestions based on empirical research is a way to measure the efficacy of institutional policy implementation, as well as the practices (if any) that support that policy decision.

\section{Conclusion}

CTP is a philosophical framework that directs attention of research on action and accountability. Research on trans* students should focus on praxis, and theory generation be closely attuned to the information provided through empirical data. Research has just begun to adequately address issues facing trans* students such as (mis)recognition and (in)visibility, as such issues impact the levels of engagement and persistence of trans* students. Attempts to theorize about trans* ${ }^{*}$ students' experience both obscure the specificity of their experiences and treat trans* oppression as a singular identity issue (Catalano \& Griffin, 2016; Dill \& Zambrana, 2009). Praxis calls attention to the interconnectedness of reflection and practice, and the previous literature on trans* inclusive policies and practices is disconnected from reflections of trans* student experiences (empirical research). I want to encourage researchers to stay closer to the words of participants to understand their experiences, to understand how oppression actually manifests in their lives. As a scholar-practitioner, I have witnessed how faculty and those in student affairs have asked meeting or class attendees to introduce themselves, including pronouns, as a form of trans* inclusion. The individual practice of pronoun sharing was identified as a supportive practice in higher education, as well as a way to create a space of support for those in the room (Jourian, Simmons, \& Devaney, 2015). I believe the intention of everyone sharing pronouns is a way to leave space for self-determination and to push back against rigid (or unclear) gender presentations and embodiments. However, I am critical of such an activity for three reasons. First, my masculine pronouns, as a person who passes as/is presumed to be a cisgender man, means my identity as trans* is invisible. Second, those who do not pass (by choice or due to limited resources) tend to be given extra scrutiny, which overemphasizes their trans*ness and, as a result, increases their sense of threat and potential for violence, physically and/or otherwise. For example, Nicolazzo, Marine, and Galarte (2015) wrote about Monica Jones, a Black trans* woman who was arrested on the erroneous charge of 'manifesting prostitution,' which is often described as 'walking while trans*'. Here, the authors contend 
that Jones - and by extension, Black trans* women, as well as other trans* and gender nonconforming people - are at greater risk and threat due to their gender transgression, especially if they do not meet normative notions of passing and/or beauty. Risks associated with disclosure of pronouns, as an introductory activity, require intentionality to avoid unintentional threats of subtle or coercive forms of violence. Third, often the request of a pronoun reveal is done without sharing the purpose. Unintended consequences of practice without explication about pronouns can lead to a number of negative consequences including a failure to understand the purpose causing pronouns to not be honored. Praxis requires reflection on action, and similarly research with praxis requires examinations of current conditions, policies, practices, and theories.

I offer that the limitations of grounded theory methods are not that theory is problematic, but that there is not yet enough to theorize. I suspect that in a few years there may be more empirical research shared and published that provides nuance and depth to broaden our understanding of trans* collegians (e.g. scholarship from trans* individuals such as T.J. Jourian, S. Simmons, and Z. Nicolazzo), which might open the possibilities for theoretical conceptualization. I encourage researchers to consider the benefit of critical theory as a way to examine theoretical connections to lived experiences, practices, and policies. I challenge those of us to who teach to complicate and trouble the epistemological frameworks that support research methods. Theorizing was problematic for my dissertation research because I thought I was bound to a positivistic approach to grounded theory methods. My discordance with grounded theory methods for my data analysis emerged from educational limitations and the inability to drawn from previous empirical research. I also encourage other scholars who are examining the lives of trans* people to make intentional choices in their methods and consider critical methods and innovative processes to avoid symbolic violence through adherence to protocols (e.g. Patel, 2016; Smith, 2012).

As I move forward in my research agenda with trans* students, I understand I must consider the connection of praxis to population-specific research. Have we examined know how trans* students view trans* inclusive non-discrimination policies? How do trans* students name or experience trans* inclusive practices? In what way(s) are the trainings created to educate our campus communities on trans* identities having an impact on student experiences? What forms of programming are effective in reaching campus populations to inform them about inclusivity, engagement, and education? Giroux (2014) argued, 'Critical thinking divorced from action is often as sterile as action divorced from critical theory' (p. 25). Social justice, CTP, and critical inquiry are frameworks that expect researchers to consider the population under examination and potentially offer actions that will address marginalization; theories are only useful to the extent that they enable and inform action.

\section{Note}

1. Transgender or trans, not trans*, were the predominant terms in use at the onset of my research.

\section{Disclosure statement}

No potential conflict of interest was reported by the author.

\section{Notes on contributor}

D. Chase J. Catalano is an assistant professor of College Student Personnel (CSP) in the Department of Education Studies at Western Illinois University. His interests include how higher education impacts, influences, and constructs: trans* identities, marginalized genders and sexualities (LGBTQ students), social justice education, engaged and dialogic pedagogies, and conceptualizations of "safe" and "ally". 


\section{References}

Backman, K., \& Kyngäs, H. A. (1999). Challenges of the grounded theory approach to a novice researcher. Nursing and Health Sciences, 1, 147-153.

Beemyn, B. (2002). The development and administration of campus LGBT centers and offices. In S. Rankin \& B. Schoenberg (Eds.), A place of our own: Lesbian, gay, bisexual, transgender services and programs in higher education (pp. 25-32). Westport, CT: Greenwood Press.

Beemyn, B. (2003). Serving the needs of transgender college students. Journal of Gay \& Lesbian Issues in Education, 1, 33-50.

Beemyn, B., Curtis, B., Davis, M., \& Tubbs, N. J. (2005). Transgender issues on college campuses. In R. L. Sanlo (Ed.), Gender identity and sexual orientation: Research, policy, and personal perspectives (pp. 49-60). San Francisco, CA: Jossey-Bass.

Beemyn, B. G. (2005). Trans on campus: Measuring and improving the climate for transgender students. On Campus with Women, 34(3) [Online]. Retrieved from http://www.aacu.org/ocww/volume34_33/feature.cfm?section=32

Beemyn, B. G., Domingue, A., Pettitt, J., \& Smith, T. (2005). Suggested steps to make campuses more trans-inclusive. Journal of Gay \& Lesbian Issues in Education, 3, 89-94.

Beemyn, B. G., \& Pettit, J. (2006). How have trans-inclusive non-discrimination policies changed institutions? GLBT Campus Matters, 3, 6-7.

Bell, L. A. (2007). Theoretical foundations for social justice education. In M. Adams, L. A. Bell, \& P. Griffin (Eds.), Teaching for diversity and social justice (2nd ed.). (pp. 1-14). New York, NY: Routledge.

Brown, S. C., Stevens, R. A., Jr., \& Troiano, P. F., \& Schneider, M. K. (2002). Exploring complex phenomena: Grounded theory in student affairs research. Journal of College Student Development, 43, 173-183.

Butler, J. (1990). Gender trouble: Feminism and the subversion of identity. New York, NY: Routledge.

Catalano, C., McCarthy, L., \& Shlasko, D. (2007). Transgender oppression. In M. Adams, L. A. Bell, \& P. Griffin (Eds.), Teachinng for diversity and social justice (2nd ed.). (pp. 219-245). New York, NY: Routledge.

Catalano, D. C. J. (2014). Welcome to guyland:Trans* men's experiences in college. Retrieved from http://scholarworks.umass. edu/dissertations_2/60/

Catalano, D. C. J. (2015a). Beyond virtual equality: Liberatory consciousness as a path to achieve trans* inclusion in higher education. Equity \& Excellence in Education, 48, 418-435.

Catalano, D. C. J. (2015b). "Trans enough?": The pressures trans men negotiate in higher education. TSQ: Transgender Studies Quarterly, 2, 411-430.

Catalano, D. C. J., \& Griffin, P. (2016). Sexism, heterosexism, and trans* oppression: An integrated perspective. In M. Adams, L. A. Bell, D. J. Goodman, \& K. Y. Joshi (Eds.), Teaching for diversity and social justice (3rd ed.). (pp. 183-211). New York, NY: Routledge.

Charmaz, K. (2006). Constructing grounded theory: A practical guide through qualitative analysis. Los Angeles, CA: Sage.

Clegg, S. (2012). On the problem of theorising: An insider account of research practice. Higher Education Research \& Development, 31, 407-418.

Corbin, J., \& Strauss, A. (1990). Grounded theory research: Procedures, canons, and evaluative criteria. Qualitative Sociology, 13, 3-21.

Currah, P., \& Stryker, S. (2015). Introduction. TSQ: Transgender Studies Quarterly, 2(1), 1-12.

Dill, B. T., \& Zambrana, R. E. (2009). Critical thinking about inequality: An emerging lens. In B. T. Dill \& R. E. Zambrana (Eds.), Emerging intersections: Race, class, and gender in theory, policy, and practice (pp. 1-21). New Brunswick, NJ: Rutgers University Press.

Freire, P. (1970/1994). Pedagogy of the oppressed. New York, NY: Continuum.

Garner, T. (2014). Becoming. TSQ: Transgender Studies Quarterly, 1, 30-32.

Giroux, H. A. (2014). Neoliberalism's war on higher education. Chicago, IL: Haymarket Books.

Gurin, P., Nagda, B. (R). A., \& Zúñiga, X. (2013). Dialogue across difference: Practice, theory, and research on Intergroup Dialogue. New York, NY: Russell Sage Foundation.

Halberstam, J. (2005). In a queer time and place: Transgender bodies, subcultural lives. New York, NY: New York University Press.

Henderson, E. F. (2014). Gender pedagogy: Teaching, learning and tracing gender in higher education. London: Palgrave Macmillian.

hooks, b. (1994). Teaching to transgress: Education as the practice of freedom. New York, NY: Routledge.

Jourian, T. J., Simmons, S. L., \& Devaney, K. C. (2015). “We are not expected”: Trans* educators (re)claiming space and voice in higher education and student affairs. TSQ: Transgender Studies Quarterly, 2, 431-446.

Love, B. J. (2010). Developing a liberatory consciousness. In M. Adams, W. J. Blumenfeld, R. Castaneda, H. W. Hackman, M. L. Peters, \& X. Zuniga (Eds.), Readings for diversity and social justice (2nd ed., pp. 599-603). New York, NY: Routledge.

Marine, S. B., \& Nicolazzo, Z. (2014). Names that matter: Exploring the tensions of campus LGBTQ centers and trans* inclusion. Journal of Diversity in Higher Education, 7, 265-281.

Maxwell, K. E., Nagda, B. (R). A., \& Thompson, M. C. (2011). Facilitating intergroup dialogues: Bridging differences, catalyzing change. Sterling, VA: Stylus Publishing.

Nicolazzo, Z. (2016). "Just go in looking good": The resilience, resistance, and kinship-building of trans* college students. Journal of College Student Development, 57, 538-556. 
Nicolazzo, Z. (in press). Trans* in college: Transgender students'strategies for navigating campus life and the institutional politics of inclusion. Sterling, VA: Stylus Publishing.

Nicolazzo, Z., Marine, S. B., \& Galarte, F. J. (2015). Introduction. TSQ: Transgender Studies Quarterly, 2, 367-375.

Pascarella, E. T. (2006). How college affects students: Ten directions for future research. Journal of College Student Development, 47, 508-520.

Pasque, P. A., Carducci, R., Kuntz, A. M., \& Gildersleeve, R. E. (2012). Qualitative inquiry for equity in higher education: Methodological innovations, implications, and interventions. In K. Ward \& L. E. Wolf-Wendel (Eds.), ASHE Higher Education Report (Vol. 37, No. 6). San Francisco, CA: Wiley Periodicals.

Patel, L. (2016). Decolonizing educational research: From ownership to answerability. New York, NY: Routledge.

Pope, R. L., Mueller, J. A., \& Reynolds, A. L. (2009). Looking back and moving forward: Future directions for diversity research in student affairs. Journal of College Student Development, 50, 640-658.

Porter, C. J., \& Dean, L. A. (2015). Making meaning: Identity development of black undergraduate women. NASPA Journal About Women in Higher Education, 8, 125-139.

Preissle, J. (2006). Envisioning qualitative inquiry: A view across four decades. International Journal of Qualitative Studies in Education, 19, 685-695.

Pusch, R. S. (2005). Objects of curiosity: Transgender college students' perceptions of the reactions of others. Journal of Gay \& Lesbian Issues in Education, 3, 45-61.

Sandelowski, M. (2000). Whatever happened to qualitative description? Research in Nursing and Health, 23, 334-340.

Sandelowski, M. (2010). What's in a name? Qualitative description revisited. Research in Nursing and Health, 33, 77-84.

Sausa, L. A. (2002). Updating college university campus policies: Meeting the needs of trans students, staff, and faculty. In E. P. Cramer (Ed.), Addressing homophobia and heterosexism on college campuses (pp. 43-55). New York, NY: Harrington Park Press.

Smith, L. T. (2012). Decolonizing methodologies: Research and Indigenous peoples (2nd ed.). London: Zed Books.

Spade, D. (2006). Compliance is gendered: Struggling for gender self-determination in a hostile economy. In P. Currah, R. M. Juang, \& S. P. Minter (Eds.), Transgender rights (pp. 217-241). Minneapolis, MN: University of Minnesota Press.

Spade, D. (2011). Normal life: Administrative violence, critical trans politics, and the limits of the law. Brooklyn, NY: South End Press.

Sullivan, N. (2006). Transmogrification: (Un)becoming others(s). In S. Stryker \& S. Whittle (Eds.), The transgender studies reader (pp. 552-564). New York, NY: Routledge.

Tompkins, A. (2014). Asterisk. TSQ: Transgender Studies Quarterly, 1, 26-27.

Vaid, U. (1995). Virtual equality: The mainstreaming of gay and lesbian liberation. New York, NY: Anchor.

Valentine, D. (2007). Imagining transgender: An ethnography of a category. Durham, NC: Duke University Press.

Young, I. M. (1990). Justice and the politics of difference. Princeton, NJ: Princeton University Press. 